\title{
Texture Characterization of Duplex Stainless Steel 2205 Using Neutron Diffraction Method
}

\author{
T. H. Priyanto*, R. Muslih, A. Insani, Bharoto, A. Ramadhani, H. Mugirahardjo \\ Center for Science and Technology of Advanced Materials, National Nuclear Energy Agency (BATAN), \\ Puspiptek Area Serpong, Tangerang Selatan 15314, Indonesia
}

\section{ARTICLE INFO}

Article history:

Received 10 March 2020

Received in revised form 2 March 2021

Accepted 8 March 2021

Keywords:

Duplex stainless steel (DSS)

Neutron diffraction

Texture

Orientation distribution function (ODF)

\begin{abstract}
A B S T R A C T
Duplex stainless steel (DSS) is widely used in chemical processes, petrochemical, oil \& gas industries, and nuclear technology due to its excellent mechanical properties and exceptional generalized and localized corrosion resistance. In this study, the crystal structure, material phases, and texture characterization of DSS were carried out using the neutron diffraction method. The characterization results show that the duplex has two phases: $\alpha$ (ferrite) and $\gamma$ (austenite), each with a lattice parameter 2.8736 Angstrom and 3.6076 Angstrom, respectively. The sample symmetrization method from triclinic to orthorhombic are used to analyze pole figures. The crystallite orientation in the $\alpha$ and $\gamma$ phases have the opposite direction. The $\alpha$ phase has a crystallite orientation towards $\{110\}<001>$ or Goss orientation, and the $\gamma$ phase, crystal orientation towards $\{100\}<001\rangle$ or the cube orientation. The orientation distribution function shows that the orientation strength of ferrite is much stronger than austenite. The crystallite orientation (texture) obtained by the orientation distribution function analysis follows the crystal structure analysis.
\end{abstract}

(C) 2021 Atom Indonesia. All rights reserved

\section{INTRODUCTION}

Duplex stainless steel (DSS) is one of the iron-based alloys used for industrial applications due to their excellent mechanical properties, generalized and localized corrosion resistance in many environments and operating conditions [1], for example, in chemical processes, petrochemical, oil $\&$ gas industries, and nuclear technology. Duplex 2205 is one of the DSS series with excellent mechanical properties and corrosion resistance [2]; however, it is prone to age hardening and brittle over a wide temperature range that depends on its grain boundaries [3]. The nickel content is essential, mainly for welding [4]; the lower nickel content, the better thermal conductivity. With nickel content above 6 wt. \%, ductility does not change with decreasing temperature. Related to the welding process, DSS does not require preheating since it can harm the nature and character of the material. If preheating has to be done, it is necessary to maintain the DSS performance before performing the

*Corresponding author.

E-mail address: thardi@batan.go.id

DOI: https://doi.org/10.17146/aij.2020.1038 mechanical work. Most of the research activities that use DSS relates to microstructure and its behavior, for example, electrochemical behavior [5], corrosion behavior [6], toughness [7], texture and microstructure evolution [8-10], sensitization effect on microstructure [11], heat input effect on microstructure [12], effects of fatigue strength and corrosion [13], and corrosion and wear properties of dissimilar welding [14]. However, DSS characterization is rarely performed using neutron diffraction method, as it needs a nuclear reactor facility. As far as the authors' finding, only a few papers appeared using the neutron diffraction method, such as DSS characteristics during loading at $200{ }^{\circ} \mathrm{C}$ [15], deformation behavior of high nitrogen, Ni-free in DSS [16], micromechanical behavior, and texture evolution [17].

The purpose of this research is to explore the texture type and strength of DSS at room temperature. It is necessary before performing a high-temperature work such as welding. One of the exciting applications of duplex welding is for nuclear power application [18]. As far as the author understood, texture characterization of DSS at room temperature using the neutron diffraction method 
has not been carried out. The characterization is performed using the neutron diffraction method utilizing BATAN's texture diffractometer (DN2). Several characterizations of stainless steel had been performed using DN2 [19,20].

\section{EXPERIMENTAL METHODS}

\section{Materials and instruments}

The material used in the present study is DSS series 2205 . We chose 2205 because its structure of ferrite and austenite compositions is approximately 50:50. It also has higher nickel and molybdenum content than other duplexes in the same family, such as 2003 and 2404 [21]. Sample plate with a thickness of $12 \mathrm{~mm}$ was bought from China, and the sample was then cut to make a cubic shape with a $12 \times 12 \times 12 \mathrm{~mm}$ size. The manufacturer's chemical composition is given and tested by the user, as shown in Table 1 . The test result shows that the chemical composition sample used for characterization is appropriate with the quality inspection certificate (QIC).

Table 1. The chemical composition of DSS2205.

\begin{tabular}{cccccc}
\hline & \multicolumn{5}{c}{ Chemical composition (\%) } \\
\cline { 2 - 6 } & $\mathbf{C}$ & $\mathbf{S i}$ & $\mathbf{M n}$ & $\mathbf{P}$ & $\mathbf{F e}$ \\
\hline Min & & & & & \\
Max & 0.03 & 1.00 & 2.00 & 0.03 & 68.0 \\
QIC & 0.021 & 0.58 & 1.47 & 0.026 & Balance \\
Test & 0.027 & 0.86 & 1.51 & 0.023 & 67.15 \\
\hline & $\mathbf{C r}$ & $\mathbf{M o}$ & $\mathbf{N i}$ & $\mathbf{S}$ & $\mathbf{N}$ \\
\hline Min & 21 & 2.5 & 4.5 & & \\
Max & 23 & 3.5 & 6.5 & & \\
QIC & 22.00 & 2.69 & 4.71 & 0.002 & 0.166 \\
Test & 22.62 & 3.00 & 4.96 & & \\
\hline
\end{tabular}

The G.A. Siwabessy nuclear research reactor produces polychromatic neutron from nuclear fission which is used for materials research. A neutron diffractometer uses a crystalline sample to investigate crystal structure, phase identification, crystallographic texture, and residual stress. It has a monochromator. The monochromator selects a neutron wavelength to produce monochromatic neutrons. After becoming monochromatic neutrons, the neutrons hit the sample and scattered in all directions. At a certain angle of scattering, the detector captures the scattered neutron, and a counting system counted the neutron captured by the detector. Then, the neutron counting system converted the neutron count into electronic pulses and then split. The neutron data obtained from the experiment were analyzed using FullProf and Labotex programs.

Figure 1 shows the texture diffractometer. (DN2). The DN2 set at a take-off angle of $2 \theta \mathrm{s}=46^{\circ}$. It uses $\mathrm{Si}$ (311) crystal as a monochromator to obtain a neutron wavelength of $\lambda_{n}=1.279 \AA$.

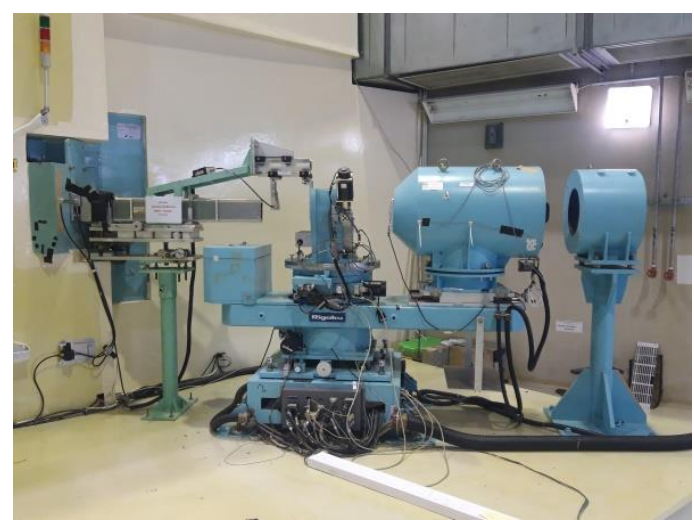

Fig. 1. The texture diffractometer (DN2).

\section{Method and procedure}

Characterization of the sample using DN2 consists of two types of scan mode. First, a $(\theta, 2 \theta)$ scan to obtain a diffraction pattern. It gave information on the sample's crystal structure and phase. Second, $(\chi, \varphi)$ scan at the $(\theta, 2 \theta)$ position to obtain a pole figure. It gave some poles related to some crystallographic lattice planes in texture materials. In the case of a cubic crystal system, three pole figures are necessary to give information on texture types and strength.

Pole figures are obtained from the experiment called experiments pole figure (EPF). From the EPF analysis, normalized pole figure (NPF), recalculated pole figure (RPF), inverse pole figure (INV), and orientation distribution function (ODF) were obtained.

The ODF describes a statistical distribution of crystallites in the sample. ODF, RPF, and IPF maps are used to interpret the texture characteristics. The ODF map used Euler space, with three rotations of crystallites represented by $g=(\varphi 1, \Phi, \varphi 2)$, where $\varphi 1$, $\Phi$, and $\varphi 2$ are called Euler angles in Bunge notation. The ODF or $f(g)$ function determines the bulk density of crystals with the $g$ orientation. The $f(g)$ unit was multiple of a random distribution (m.r.d), i.e., if $f(g)=1$, it corresponds to the random orientation of crystals or sample without texture. To calculate the ODF, two groups of the method are used, either indirect method, direct method, or arbitrarily defined cells (ADC) method.

The indirect method used the Fourier series analysis. According to the direct method, there may 
additionally exist another type of symmetry, so-called "sample symmetry" (S.S.). There were possibly three types of sample symmetry with point groups: $\mathrm{C}_{1}, \mathrm{C}_{2}, \mathrm{D}_{2}$. The elementary or basic regions in theirs range of the ODF space with Euler angles space $\left(\varphi_{1}, \Phi, \varphi_{2}\right)$ for the groups $\mathrm{G}_{\mathrm{c}}$ of crystal system (C.S.) (crystal symmetry) and groups $\mathrm{G}_{\mathrm{s}}$ of sample system (S.S.) (sample symmetry) explained by Pawlik [22]. According to crystal and sample symmetries, the Euler angles of materials with cubic crystal symmetry and orthorhombic sample symmetries were in the range $(\varphi 1, \Phi, \varphi 2) \in\left(0^{\circ} ; 90^{\circ}\right)$. FullProf and Labotex software [23] were used to analyzed crystal structure and pole figure, respectively.

\section{RESULTS AND DISCUSSION}

\section{Crystal structure analysis}

BATAN's texture diffractometer (DN2) was used to characterize 2205 samples at room temperature. It uses a neutron wavelength of $1.279 \AA$ to obtain a diffraction pattern of the sample. Figure 2 shows a diffraction pattern with dual phases, ferrite $\alpha$-phase with BCC structure, and austenite $\gamma$-phase with FCC structure. For data analysis, Fullprof was used to refine lattice parameters and other parameters. Table 2 shows the Bragg peak position of $\alpha$-phase and $\gamma$-phase. Lattice parameter of $\alpha$-phase, $\quad \mathrm{a}=2.8736 \AA$ with preferred orientation $\mathrm{G} 1=-2.14 \pm 0.03$, and for $\gamma$-phase, the lattice parameters are $\mathrm{a}=3.6076 \AA$ with $\mathrm{G} 1=0.35 \pm 0.03$.

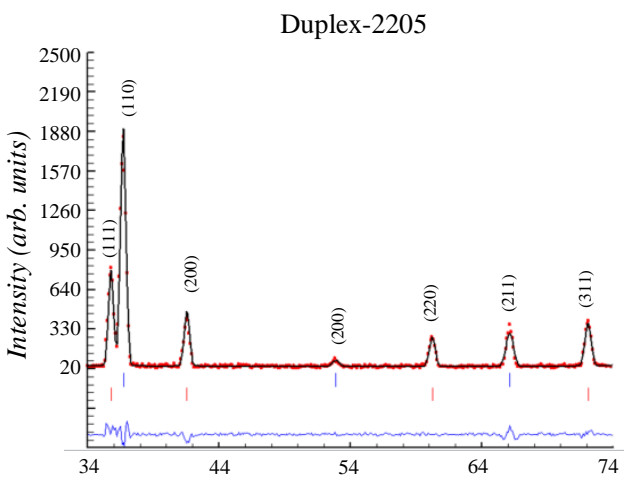

(a)

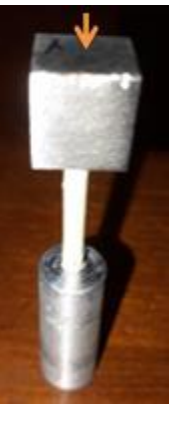

(b)
Fig. 2. (a) Neutron diffraction of DSS 2205 diffracted from cutting plane position of the sample. The red tick (|) and the black tick ( |) are the Bragg peaks for the $\gamma$ phase and $\alpha$ phase, respectively; (b). Cubic shape of the DSS 2205 sample. The top of the sample is the cutting plane.

It shows that the sample has a crystallite orientation for both phases, with different orientation directions. Capek [24] also shows the existence of preferred orientation. From Rietveld analysis, the reliability factors are $\mathrm{Rp}=15.2 \%, \mathrm{Rwp}=17.1 \%, \mathrm{Re}=14.1 \%$, and goodness of fit $\chi^{2}=1.458$. The $\sigma$ and $\chi$ phases do not appear in the characterization at room temperature. These phases appear only at high temperatures [3].

Table 2. The Bragg peaks position, (hkl) index, and phase types ( $\alpha$ and $\gamma$ phase).

\begin{tabular}{cccc}
\hline Peaks & $\mathbf{2 \theta}(\mathbf{d e g})$ & $(\mathbf{h k l})$ & Phases \\
\hline 1 & 35.7845 & $(111)$ & $\gamma$ \\
2 & 36.7137 & $(110)$ & $\alpha$ \\
3 & 41.5571 & $(200)$ & $\gamma$ \\
4 & 52.8959 & $(200)$ & $\alpha$ \\
5 & 60.2253 & $(220)$ & $\gamma$ \\
6 & 66.1153 & $(211)$ & $\alpha$ \\
7 & 72.0726 & $(311)$ & $\gamma$ \\
\hline
\end{tabular}

\section{Texture analysis}

\section{Pole figures}

Texture characterization used pole figures of ferrite $\alpha$-phase (110), (200), (211), and austenite $\gamma$-phase (111), (200), (220). Table 2 shows some Bragg peaks and Miller index related for each phase. Scan $(\chi, \phi)$ in the range of $0^{\circ} \leq \chi \leq 70^{\circ}$, and $0^{\circ} \leq \phi$ $\leq 355^{\circ}$ are taken to get one pole figure. The texture component of the ferrite $\alpha$-phase obtained from the pole figures refinement is $\{110\}<001>$ or Goss orientation. Figure 3 shows the pole figures of $\alpha$ phase. Goss orientation or cubic-on-edge orientation gives $\langle 001\rangle||$ RD and $\langle 011\rangle||$ ND. Figure 4 shows the texture component of the austenite $\gamma$-phase, which has $\{001\}\langle 100\rangle$, or Cubic orientation. The ferrite ( $\alpha$-phase) exhibits a relatively stronger texture than austenite ( $\gamma$-phase). It revealed well-defined initial textures in both constituent $\alpha$ and $\gamma$-phases.

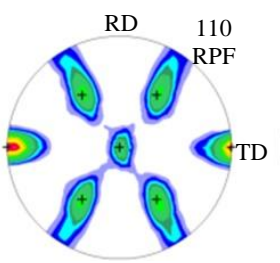

Duplex-BM-FerPh

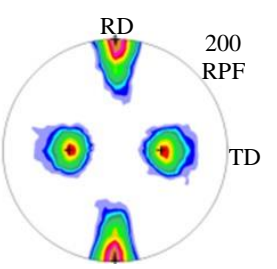

Duplex-BM-FerPh

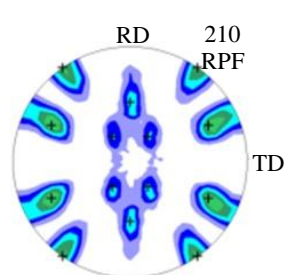

Duplex-BM-FerPh

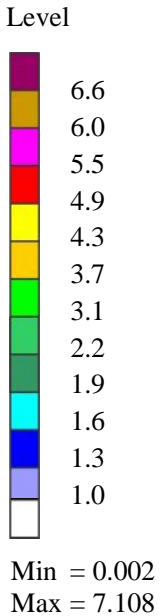

$\operatorname{Max}=7.108$
Fig. 3. Recalculated pole figures (RPF) of (110), (200), and (211) for ferrite $\alpha$-phase. 
However, the texture type is contrary to the texture measurement conducted after preliminary thermomechanical [25]. In the case of the $\alpha$-phase, the mutual influence of $\alpha$ and $\gamma$ phases and mainly different mechanical properties of both phases result in the limitation of rotation of $\alpha$ grains during deformation. During rolling, the stronger phase $(\alpha)$ keeps energy until deformation exceeds a certain limit. Therefore, the $\alpha$-phase has a stronger orientation distribution function value compared to the $\gamma$ phase.

A study on SS2205 performed by Baczmański [26] shows a similar result with our result of texture in the austenite component $\{001\}<001>$; however, there is a different ferrite texture that shows $\{001\}<110\rangle$. It probably because of the rolling process during manufacture or slip deformation in the ferrite component.

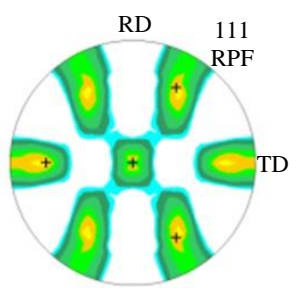

Duplex-BM-AusPh

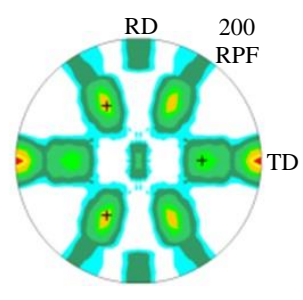

Duplex-BM-AusPh

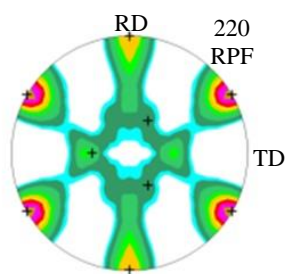

Duplex-BM-AusPh

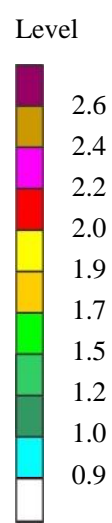

$\operatorname{Min}=0.399$ $\operatorname{Max}=2.623$
Fig. 4. Recalculated pole figures (RPF) of (111), (200), and (220) for the austenitic $\gamma$-phase.

\section{Orientation Distribution Function (ODF)}

Sample symmetrization was used for ODF calculation from triclinic $\left(\mathrm{C}_{1}\right)$ to orthorhombic $\left(\mathrm{D}_{2}\right)$. The range of triclinic $\left(C_{1}\right)$ is $0^{\circ} \leq \varphi_{1} \leq 360^{\circ}, 0^{\circ} \leq \Phi \leq 180^{\circ}$, and $0^{\circ} \leq \varphi_{2} \leq 360^{\circ}$. The range of orthorhombic $\left(\mathrm{D}_{2}\right)$ is $0^{\circ}$ $\leq \varphi_{1} \leq 90^{\circ}, 0^{\circ} \leq \Phi \leq 90^{\circ}, 0^{\circ} \leq \varphi_{2} \leq 180^{\circ}$. In the ODF calculation, the ODF value takes the strongest texture. Figure 5 shows ODF for ferrite $\alpha$-phase with $\Delta=5^{\circ}$, and Table 3 shows orientation type and orientation in the basic region of ferrite $\alpha$-phase. From the ODF calculation, the ferrite $\alpha$-phase component has an average ODF value $=30.737$ m.r.d on (110) [001] or Goss orientation, in the Euler space $(90,90,45)$, whereas the austenite $\gamma$-phase has the average ODF value $=5,149$ m.r.d. on (010) [001] and (100) [0-10] or Cube orientation, with Euler space $(0,90,0)$ and $(0,90,90)$, respectively.

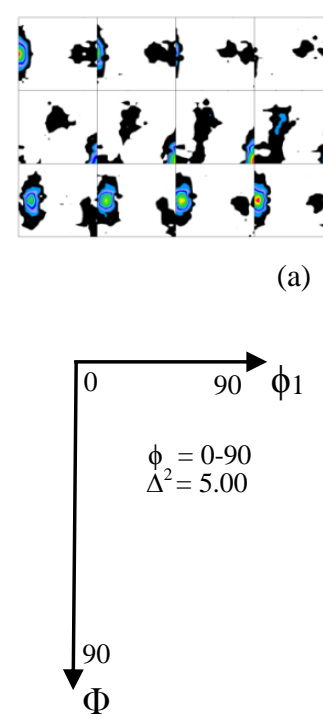

(b)
Duplex_BM_FerPh Levels

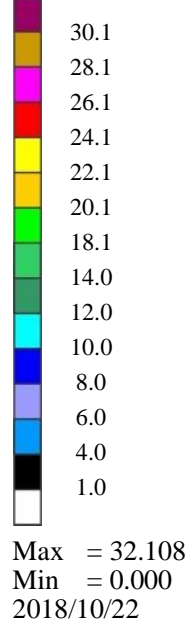

(c)
Fig. 5. (a). ODF of ferrite $\alpha$-phase component; (b). Euler space for ODF representation; (c). Level of multiple random distributions (m.r.d)

Table 3. Orientation type and orientation in the basic region of the ferrite $\alpha$-phase.

\begin{tabular}{|c|c|c|c|c|c|}
\hline & mmetry & \multicolumn{4}{|c|}{ O Cubic } \\
\hline \multicolumn{2}{|c|}{ Orientation type } & $\multicolumn{4}{|c|}{110}<001\rangle$ \\
\hline & Name & \multicolumn{4}{|c|}{ Goss } \\
\hline \multicolumn{2}{|c|}{ ODF (average) } & \multicolumn{4}{|c|}{30.737} \\
\hline \multicolumn{6}{|c|}{ Orientation in the basic region } \\
\hline $\mathbf{N}$ & (HKL)[UVW] & $\varphi 1$ & $\Phi$ & $\varphi 2$ & ODF \\
\hline 1 & $(110)[001]$ & 90 & 90 & 45 & 32.108 \\
\hline 2 & $(011)[100]$ & 0 & 45 & 0 & 30.054 \\
\hline 3 & $(101)[001]$ & 0 & 45 & 90 & 30.054 \\
\hline
\end{tabular}

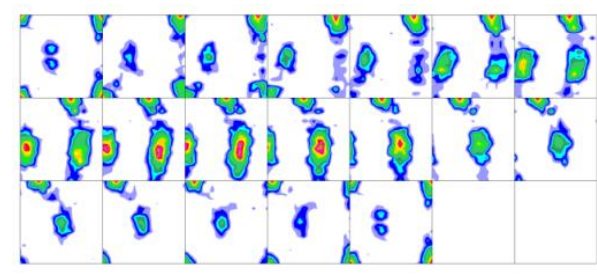

(a)

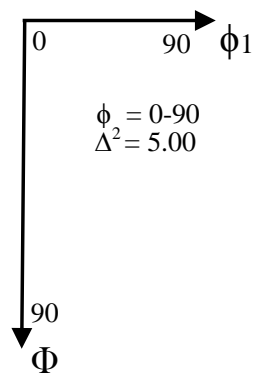

(b)
Duplex_BM_At Levels

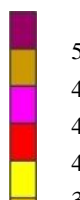

5.1

4.8

4.4

4.1

3.8

3.4

3.1

2.4

2.1

1.8

1.1

$\operatorname{Max}=5.433$

Min $=0.120$

$2018 / 10 / 22$

(c)
Fig. 6. (a). ODF of the austenite $\gamma$-phase component; (b). Euler space for ODF representation; (c). Level of multiple random distributions (m.r.d). 
Figure 6 shows the ODF for the austenite $(\gamma$-phase with $\Delta=5^{\circ}$, and Table 4 shows orientation type and orientation in the basic region of the austenite $\gamma$-phase.

Table 4. Orientation type and orientation in a basic region of the austenite $\gamma$-phase.

\begin{tabular}{cccccc}
\hline \multicolumn{1}{c}{ Symmetry } & \multicolumn{5}{c}{ O Cubic } \\
\hline \multicolumn{3}{c}{ Orientation type } & \multicolumn{5}{c}{ cube $\}<100>$} \\
\hline \multicolumn{3}{c}{ Name } \\
\hline \multicolumn{3}{c}{ ODF (average) } \\
\hline \multicolumn{3}{c}{ Orientation in the basic region } \\
\hline No & (HKL)[UVW] & $\boldsymbol{\varphi}_{1}$ & $\mathbf{\Phi}$ & $\boldsymbol{\varphi}_{2}$ & ODF \\
\hline 1 & $(010)[100]$ & 0 & 90 & 0 & 5.224 \\
2 & $(100)[0-10]$ & 0 & 90 & 90 & 5.224 \\
3 & $(010)[001]$ & 90 & 90 & 0 & 5.222 \\
4 & $(100)[001]$ & 90 & 90 & 90 & 5.222 \\
5 & $(001)[0-10]$ & 90 & 0 & 0 & 5.133 \\
6 & $(001)[-100]$ & 90 & 0 & 90 & 5.133 \\
7 & $(001)[100]$ & 0 & 0 & 0 & 5.019 \\
8 & $(001)[010]$ & 0 & 0 & 90 & 5.019 \\
\hline
\end{tabular}

\section{CONCLUSION}

Texture characterization of DSS 2205 at room temperature using the neutron diffraction method shows a dual-phase with different texture types and strengths, namely ferrite $\alpha$-phase and austenite $\gamma$-phase with Goss and Cube orientation, respectively. Ferrite texture is stronger than austenite. These results are comparable to the results obtained from the crystal structure and texture analysis. This information is essential for welding applications, mainly using the friction stir welding (FSW) method. So that for the future, welding duplex using FSW is interesting.

\section{ACKNOWLEDGMENT}

The research project is supported by the DIPA 2018 as a part of research activities in the Neutron Beam Technology Division, PSTBM, BATAN. The author would like to thank the researchers and technicians in the support system division for preparing the sample, equipment, and others.

\section{AUTHOR CONTRIBUTION}

Tri Hardi Priyanto contributed as the main contributor of this paper. All authors read and approved the final version of the paper.

\section{REFERENCES}

1. F. Iacoviello, V. Di Cocco, E. Franzese et al., Procedia Struct. Integr. 3 (2017) 308.

2. F. Iacoviello, V. Di Cocco and L. D' Agostino, Procedia Struct. Integr. 3 (2017) 276.

3. V. Di Cocco, F. Iacoviello and G. Ischia, Procedia Struct. Integr. 3 (2017) 299.

4. J. Pilhagen and R. Sandström, Mater. Sci. Eng. A 602 (2014) 49.

5. M. A. Makhdoom, A. Ahmad, M. Kamran et al., Surf. and Interfaces 9 (2017) 189.

6. S. Geng, J. Sun, L. Guo et al., J. Manuf. Process. 19 (2015) 32.

7. Z. Zhang, H. Jing, L. Xu et al., J. Manuf. Process. 31 (2018) 568.

8. P. O. Malta, F. L. Dias, A. C. M. de Souza et.al., Mater. Charact. 142 (2018) 406.

9. S. Emami, T. Saeid, R. A. Khosroshahi and J. Alloys Compd. 739 (2018) 678.

10. G. M. Xie, H. B. Cui, Z. A. Luo et al., Mater. Sci. Eng. A 704 (2017) 311.

11. L. Jinlong, L. Tongxiang, D. Limin et al., Corros. Sci. 104 (2016) 144.

12. G. R. Mohammed, M. Ishak, S. N. Aqida et al., Metals. 7 (2017).

13. D. Reyes-Hernández, A. Manzano-Ramírez, A. Encinas et al., Fuel 198 (2017) 165.

14. Y. Choi, Y. Baik, B. M. Moon et al., Nucl. Eng. Technol. 48 (2016) 164.

15. R. Dakhlaoui, A. Baczmański, C. Braham et al., Mater. Sci. Forum 571-572 (2008) 175.

16. T. H. Lee, H. Y. Ha, J. Y. Kang et al., Scr. Mater. 67 (2012) 141.

17. N. Jia, R. L. Peng, Y. D. Wang et al., Acta Mater. 56 (2008) 782.

18. J. D. Tucker, M. K. Miller and G. A. Young, Acta Mater. 87 (2015) 15.

19. T. H. Priyanto, R. Muslih, H. Mugirahardjo et al., Makara J. Technol. 22 (2018) 79.

20. T. H. Priyanto, R. Muslih, H. Mugiraharjo et al., Jurnal Sains Materi 19 (2018) 120.

21. K. T. Nirosta, Practical Guidelines for the Fabrication of Duplex Stainless Steels, $3^{\text {rd }}$ ed., International Molybdenum Association, London (2014) 1. 
22. K. Pawlik, Introduction to LaboTex, in: Texture Analysis Software for Windows, LaboTex Version 3.0, LaboSoft s.c., Krakow (2011) 1.

23. K. Pawlik, Fundamentals of 3-D Texture Analysis. Symmetry aspects of 3-D texture analysis, in: The Texture Analysis Software for Windows, LaboTex Version 3.0, LaboSoft s.c., Krakow (2006) 1.
24. J. Capek, M. Cernik, N. Ganev et al., IOP Conf. Ser. Mater. Sci. Eng. 375 (2018) 1.

25. N. Jia, R. L. Peng, Y. D. Wang et al., Acta Mater. 56 (2008) 782.

26. A. Baczmański, E. Gadalińska, S. Wroński et al., Mater. Sci. Forum 768-769 (2013) 289. 